\title{
Study on Cuttings Transport Efficiency Affected by Stabilizer's Blade Shape in Vertical Wells
}

\author{
Sun Xiaofeng*, ${ }^{, 1}$, Yan Tie ${ }^{1}$, LiWei $^{1}$ and WuYanze ${ }^{2}$ \\ ${ }^{I}$ College of Petroleum Engineering, Northeast Petroleum University, Daqing, Heilongjiang, China; ${ }^{2}$ Sinopec \\ International Petroleum Service Corporation, Beijing, China
}

\begin{abstract}
Effective cuttings transport means a better hole cleaning in drilling operations, which can increase the rate of penetration (ROP), and avoids pipe sticking, higher drag and torque problems. This paper aimed to analyze cuttings transport efficiency affected by different blade shapes of stabilizers, which is often overlooked in drilling. For this purpose, Eulerian multiphase flow model was used to simulate the influence of different blade types of stabilizers on cuttings transport efficiency under rotating coordinates. Numerical simulations indicate that straight blade stabilizer is obviously superior to helical blade for cuttings transport efficiency in vertical wells using the same hydraulic parameter and rotating speed. Field tests were conducted in some medium-deep wells of Daqing Oil Field, and the results showed that repeated fragmentation of cuttings, bit balling and pipe sticking problems were improved, and ROP was obviously raised.
\end{abstract}

Keywords: Stabilizer, blade type, cuttings transport, rotating coordinates, solid-fluid coupling

\section{INTRODUCTION}

Effective cuttings transport is the major consideration in the design of hydraulic parameters and any stage of drilling operations. Inadequate cuttings transport capacity may cause serious problems, such as pipe sticking, higher torque and drag, and bit balling, etc. Many experimental studies and field experience showed that the effective cuttings transport depends largely on annulus velocity of drilling fluid, drilling fluid rheology, deviation angle, drillstring rotating speed, penetration rate, eccentricity of drillstring, cutting size[1-4], however, blade shape of stabilizer is a very influential factor, but often overlooked in hydraulic design and drilling operations. Stabilizer is a drillstring sub which is mounted on the top of bit and used with drill collar. It ensures that drillstring rotates along borehole axis or approximate axis to achieve well path control in directional wells and deviation control in vertical wells [5] by keeping its outside diameter close to borehole diameter [6]. Stabilizer has two types based on the blade shape, including helical blade and straight blade. Helical blade stabilizer has larger surface area to make sure there is enough contact with borehole wall, and it is easier to generate eddy to enhance cuttings transport efficiency to some extent, especially for High-Angle and horizontal Wells [7]. On the contrary, surface area of straight blade stabilizer is less than helical one; it has the advantage of less pipe sticking and lower frictional resistance. In general, blade type selection criteria will consider the following three factors: formation lithology, cuttings transport efficiency and hole deviation control; hole

*Address corresspondence to this author at the Daqing high-tech industrial development zone No.199, Daqing, Heilongjiang province, China; Post code: 163318; Tel: 0459-6503521; Fax: 0459-6503482;

E-mails: suneye@126.com; 493688306@qq.com deviation control issues usually top the priority list [8]. However, using stabilizer greatly reduces annulus area for drilling fluid as well as cuttings transport efficiency. Especially, studies show the outside profile of stabilizers' blade greatly affects cuttings transport $[9,10]$. Unreasonable blade shape may lead to bad cuttings transport, back flow, repeated fragmentation, and bit balling; all of these issues will decrease ROP, but few studies have been carried out for the influence on cuttings transport efficiency affected by blade type in vertical wells. This paper applies Eulerian multiphase flow model to simulate cuttings transport efficiency of two blades in vertical annulus under the rotating coordinate. The conclusion has been verified in field tests.

\section{THE FULL-SIZE STABILIZER SIMULATION AND GRID MESHING}

Numerical simulation model is based on the four-blade PDC bit and near-bit stabilizer which were used in mediumdeep wells of Daqing Oil Field. The 3D geometry of the model was imported to CFD software for calculations. The model dimensions are shown in Table $\mathbf{1}$, and the model profile in Fig. (1). Mixed grids are applied in the process of generating grids see Fig. (2). The model uses unstructured grid in the flow field near bit and stabilizer, and uses structured grid in other regular flow field to accelerate the convergence. Total grids of the model are up to about 500 thousand.

\section{CONSERVATION EQUATIONS UNDER THE RO- TATING COORDINATE}

\section{Steady-state Conservation Equations under the Rotating Coordinate}

Under rotatory drilling condition, fluid nearby the corresponding flow domain forms annular spiral flow 
Table 1. The bit and stabilizer dimensions.

\begin{tabular}{|c|c|c|}
\hline Bit parameters & $\begin{array}{c}\text { Straight blade stabilizer } \\
\text { parameters }\end{array}$ & $\begin{array}{c}\text { helical blade stabilizer } \\
\text { parameters }\end{array}$ \\
\hline Height: $400 \mathrm{~mm}$ & blade length: $500 \mathrm{~mm}$ & blade length: $500 \mathrm{~mm}$ \\
\hline Number of nozzles: 6 & blade height: $32 \mathrm{~mm}$ & blade height: $36 \mathrm{~mm}$ \\
\hline $\begin{array}{c}\text { Nozzle equivalent } \\
\text { size: } 15 \mathrm{~mm}\end{array}$ & $\begin{array}{c}\text { width between centers: } \\
1320 \mathrm{~mm}\end{array}$ & $\begin{array}{c}\text { width between centers: } \\
1320 \mathrm{~mm}\end{array}$ \\
\hline $\begin{array}{c}\text { Number of blade: } 4 \\
\text { stabilizer length: } \\
1530 \mathrm{~mm}\end{array}$ & $\begin{array}{c}\text { stabilizer length: } \\
1530 \mathrm{~mm}\end{array}$ \\
\hline
\end{tabular}

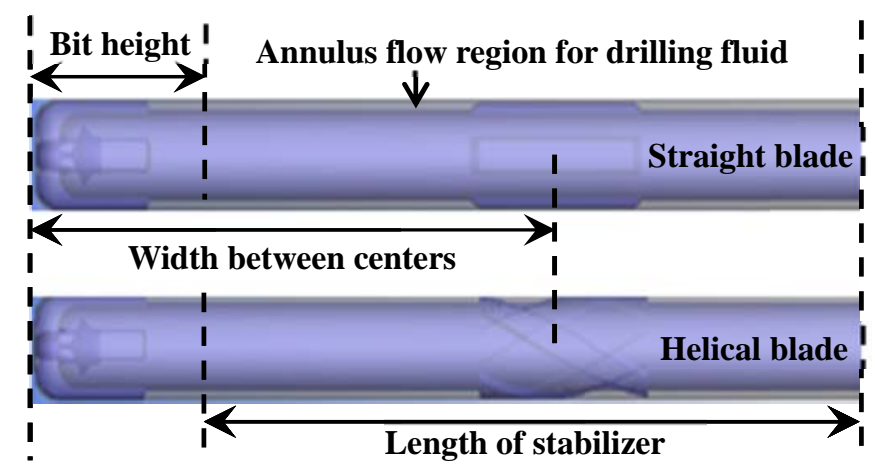

Fig. (1). The full-size stabilizer model.

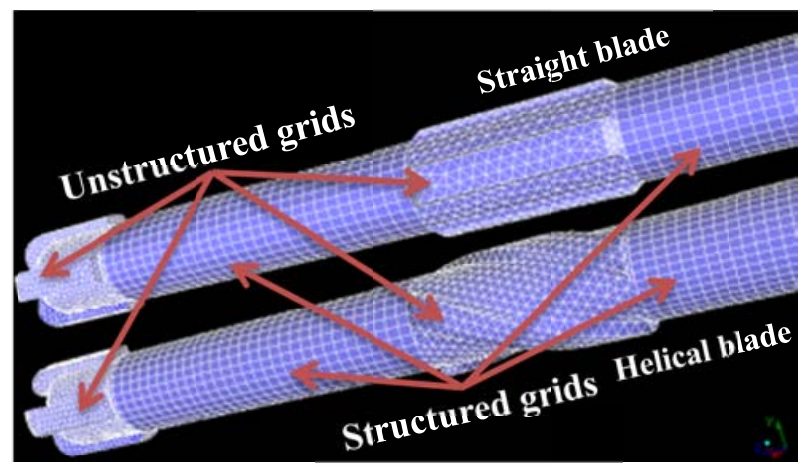

Fig. (2). 3D grid configuration.

because of the bit and blade of stabilizer rotating with high velocity. The relative velocity and the angel of path lines to rotatory blade can be simulated under rotating coordinate when only liquid phase passes through the flow field. Steady state N-S equations are used in this simulation in order to qualitatively analyze cuttings transport efficiency affected by rotatory blade. That is, the flow domain and coordinate system rotate with fixed angular velocity. Viscous model applies the RNG $k$ - ̊̊ model. Pressure and velocity coupling scheme apply SIMPLE method [11], and spatial discretization scheme of momentum equations uses the firstorder upwind.

\section{Conservation of Mass}

$\nabla \cdot v_{\mathrm{r}}=0$

\section{Conservation of Momentum}

$\nabla \cdot\left(\rho_{\mathrm{l}} \boldsymbol{v}_{\mathrm{r}} \boldsymbol{v}_{\mathrm{r}}\right)+\rho_{\mathrm{l}}\left(2 \omega \times \boldsymbol{v}_{\mathrm{r}}+\omega \times \omega \times \boldsymbol{r}\right)=-\nabla p+\mu \nabla^{2} \boldsymbol{v}_{\mathrm{r}}+\rho_{\mathrm{l}} \boldsymbol{g}$

Where: $\boldsymbol{\omega}$ - angular velocity under rotary coordinate system, rpm;

$\boldsymbol{v}_{\mathrm{r}}$ - relative velocity of flow region under rotary coordinate system, m/s;

$\boldsymbol{r}$ - radius vector under rotary coordinate system, $\mathrm{m}$;

$\rho_{l}$ - drilling fluid density, $\mathrm{g} / \mathrm{cm}^{3}$.

Transient Solid-fluid Coupling Flow Conservation Equations under the Rotating Coordinates

Transient solid-fluid coupling simulation uses Eulerian multiphase model under rotating coordinate, which solves mass and momentum equations for each phase respectively, and pressure is shared by all phases. The simulation is intended to analyze how the blade types affect annular solid cuttings transport efficiency and the probability of cuttings pass through stabilizers versus time. The sliding grids and the real-time updating grids are used to solve the change law of transient flow field. Viscous model, pressure and velocity coupling and spatial discretization scheme are same as steady-state simulations.

\section{Solid-fluid Conservation of Mass}

$\frac{\partial}{\partial t}\left(\alpha_{l} \rho_{l}\right)+\nabla \cdot\left(\alpha_{l} \rho_{l} v_{l}\right)=\Delta \mathrm{m}_{s l} \cdots$

$\frac{\partial}{\partial t}\left(\alpha_{s} \rho_{s}\right)+\nabla \cdot\left(\alpha_{s} \rho_{s} v_{s}\right)=\Delta \mathrm{m}_{l s} \cdots$

\section{Liquid Phase Conservation of Momentum}

$\frac{\partial}{\partial \mathrm{t}}\left(\alpha_{l} \rho_{l} \mathbf{v}_{l}\right)+\nabla \cdot\left(\alpha_{l} \rho_{l} \mathbf{v}_{l} \mathbf{v}_{l}\right)=-\alpha_{l} \nabla p+\mu \nabla^{2} \mathbf{v}_{l}+\alpha_{l} \rho_{l} \mathbf{g}+K_{s l}\left(\mathbf{v}_{s}-\mathbf{v}_{l}\right)+\Delta \mathrm{m}_{s l} \mathbf{v}_{s l}-\Delta \mathrm{m}_{l s} \mathbf{v}_{l s}$

\section{Solid Phase Conservation of Momentum}

$\frac{\partial}{\partial \mathrm{t}}\left(\alpha_{s} \rho_{s} \mathbf{v}_{s}\right)+\nabla \cdot\left(\alpha_{s} \rho_{s} \mathbf{v}_{s} \mathbf{v}_{s}\right)=-\alpha_{s} \nabla p+\mu \nabla^{2} \mathbf{v}_{s}+\alpha_{s} \rho_{s} \mathbf{g}+K_{l s}\left(\mathbf{v}_{l}-\mathbf{v}_{s}\right)+\Delta \mathrm{m}_{l s} \mathbf{v}_{l s}-\Delta \mathrm{m}_{s l} \mathbf{v}_{s l}$

Where " $s$ " and " $l$ " are the subscripts which represent solid and liquid phase parameters. $\Delta \mathrm{m}_{s l}$ is the mass transfers from solid phase to fluid phase. Similarly, the place change of subscripts represents the mass transfers from fluid phase to solid phase. Furthermore, $\Delta \mathrm{m}_{s l}=-\Delta \mathrm{m}_{l s} ; v_{l s}$ is the velocity between phases. When $\Delta \mathrm{m}_{l s}>0, \boldsymbol{v}_{l s}=\boldsymbol{v}_{s l}$. When $\Delta \mathrm{m}_{l s}<0, \boldsymbol{v}_{l s}=\boldsymbol{v}_{s}$ and $v_{l s}=v_{s l} ; \alpha$ is the phase volume fraction, and it is no dimensional; $K_{s l}$ is the solid-liquid momentum interchange coefficients, $K_{\mathrm{s} l}=\alpha_{s} \rho_{s} f / \tau_{s}, \tau_{s}$ is the relaxation time of particles, $\tau_{s}=\rho_{s} d_{s}^{2} / 18 \mu_{l}, \quad K_{l s}=K_{s l}$, which derives from Syamlal-O'Brien model [12] is the drag force function.

\section{BOUNDARY AND INITIAL CONDITIONS}

Boundary conditions of the steady-state simulation are set by velocity inlet, pressure outlet and the standard wall function. The main operating data is given in Table 2 .

Inlet velocity of drilling fluid is consistent with pump speed 80SPM, 100SPM and 120SPM of FM-1300 piston pump respectively, which is used in Daqing Oil Field. Sliding grids rotate speed is controlled in 120rpm to simulate normal drilling string rotation; meanwhile, the grids in rigid 
Table 2. Boundary and initial conditions

\begin{tabular}{|c|c|c|c|c|c|c|}
\hline $\begin{array}{c}\text { Inlet velocity } \\
\text { series, } \mathbf{m} / \mathbf{s}\end{array}$ & $\begin{array}{c}\text { Pressure } \\
\text { outlet, Pa }\end{array}$ & $\begin{array}{l}\text { Drilling fluid } \\
\text { density, } \mathrm{g} / \mathrm{cm}^{3}\end{array}$ & $\begin{array}{c}\text { Cuttings } \\
\text { diameter, } \mathrm{mm}\end{array}$ & $\begin{array}{l}\text { Initial cuttings } \\
\text { bed height, mm }\end{array}$ & $\begin{array}{c}\text { Rotating speed, } \\
\text { rpm }\end{array}$ & $\begin{array}{c}\text { Deviation angle, } \\
\text { degree }\end{array}$ \\
\hline $\begin{array}{c}5.46 \\
6.83 \\
8.2\end{array}$ & 101325 & 1.2 & 2 & 30 & 120 & $0^{\circ}$ \\
\hline
\end{tabular}

rotation are updated in real time. Cuttings bed is patched at bottom as initial condition.

\section{SIMULATION ANALYSIS AND FIELD TESTS}

\section{Steady-state Flow Field Distribution under Rotary Coordinate System}

In the steady-state simulations, pump rate and drilling string rotation speed are fixed, and the flow field of drilling fluid is distributed normally. Fig. (3) shows the velocity distribution of drilling fluid path lines relative to the stabilizer, some path lines impact helical blade, and bent with a large angle. According to the path lines observation, solid cuttings are not easier to pass through the helical stabilizers due to a collisions might be happen between cuttings and blades, which makes cuttings transport efficiency decrease. However, the straight blade stabilizer makes path lines present a small angle deflection, and it means cuttings are easier to pass through the straight one, and takes less time to cross it. The flow field analysis indicates that under the rotating condition, the straight blade stabilizer is obviously better than helical blade stabilizers for cuttings transport efficiency.

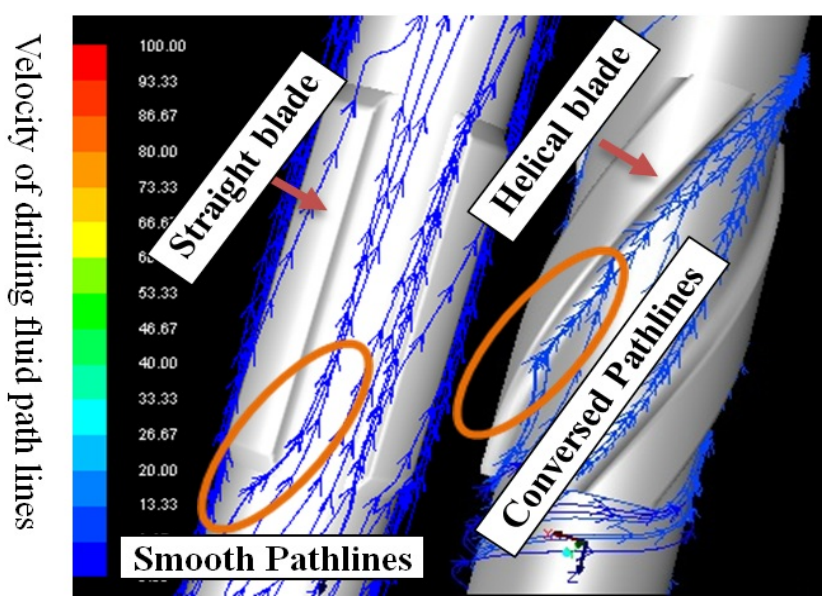

Fig. (3). Velocity distribution of drilling fluid path lines relative to the rotary coordinate system.

\section{The Contrastive Analysis of Transient Cuttings Transport Efficiency}

Transient simulation scheme of cuttings transport process is applied to erode cuttings bed initial condition of which is $30 \mathrm{~mm}$ height at bottom of the hole, as it is shown in Fig. (4). Dynamic mesh is applied to update time to observe the efficiency of cuttings passing through the stabilizers blade. Under the same condition, the time that it takes for cuttings to completely pass through two blades is regarded as evaluating indicator of cuttings transport efficiency.
Simulation results show a great agreement with steadystate prediction. Solid cutting particles were quickly driven out from the bottom of hole when cuttings bed is flushed by high-speed jet of the bit in helical blades stabilizer simulation. After particles enter into the junk slot of helical blades, there repeatedly turns up the elastic collisions between particles and the helical blades. Due to the elastic collisions, part of particles flows back into the junk slot as shown in Fig. (5), which greatly reduces the cuttings transport efficiency because of repeated fragmentation of cuttings. On the contrary, cuttings are finely dispersed when particles pass through the junk slot of straight blades. The collision frequency between cuttings and the blades is obviously lower than helical blades. Compared with the helical blade stabilizer, it takes less time for cuttings to pass through. In different pump displacement conditions, the time-consuming curves of cuttings completely pass through the two blades from cuttings bed that are shown in Fig. (6). The transient simulation shows the consuming-time of straight blade stabilizer is reduced by $200 \%$ $300 \%$ compared with helical one. It means straight blade stabilizer can achieve higher cuttings transport efficiency in vertical drilling operations.

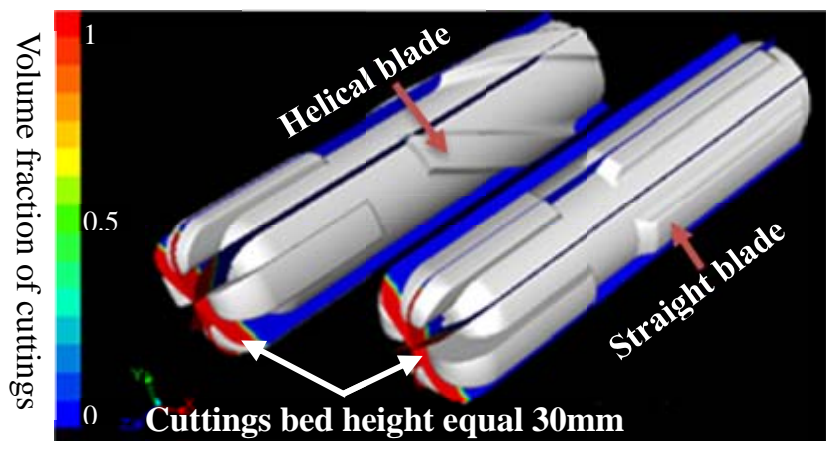

Fig. (4). Initial condition of the transient simulation.

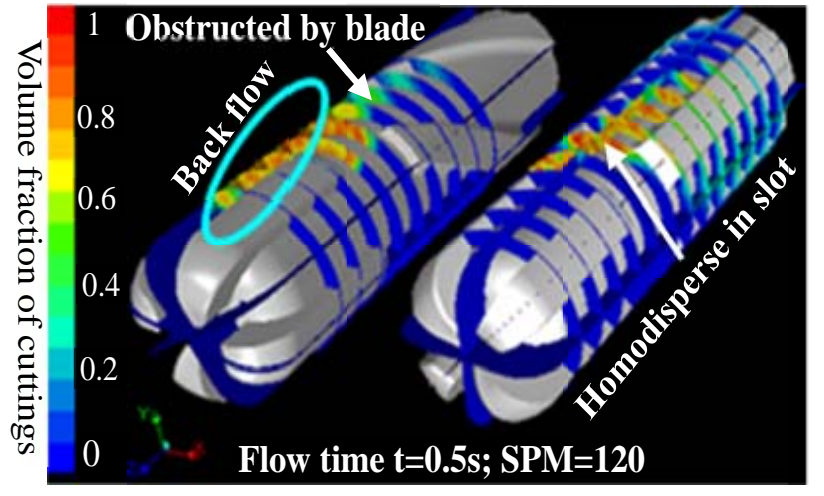

Fig. (5). Cuttings dispersion characteristics of two types of stabilizers (displacement is $120 \mathrm{SPM}$ ). 
Table 3. Test data in Daqing medium-deep wells

\begin{tabular}{|c|c|c|c|c|c|c|c|c|c|}
\hline Wells & Formation & $\begin{array}{c}\text { Drilling } \\
\text { depth (m) }\end{array}$ & $\begin{array}{c}\text { bit weight } \\
\text { (KN) }\end{array}$ & $\begin{array}{c}\text { Rotation } \\
\text { speed } \\
\text { (r/min) }\end{array}$ & $\begin{array}{c}\text { Displacement } \\
(\mathrm{L} / \mathrm{s})\end{array}$ & $\begin{array}{c}\text { Pump } \\
\text { pressure } \\
\text { (MPa) }\end{array}$ & $\begin{array}{l}\text { Blade } \\
\text { types }\end{array}$ & $\begin{array}{l}\text { Drilling } \\
\text { time } \\
(\mathbf{m i n} / \mathbf{m})\end{array}$ & $\begin{array}{c}\text { ROP } \\
\text { enhancing } \\
\text { range }\end{array}$ \\
\hline $\mathrm{Pu} 1$ & Quan 3 & 285 & 50 & 180 & 34 & 12 & helical & 1.97 & \multirow{2}{*}{$45.6 \%$} \\
\hline Wang 1 & Quan 3 & 225 & 60 & 120 & 38 & 14 & straight & 1.07 & \\
\hline $\mathrm{Pu} 1$ & Quan 4 & 255 & 50 & 180 & 34 & 12 & helical & 2.58 & \multirow{2}{*}{$15.1 \%$} \\
\hline $\mathrm{Pu} 2$ & Quan 4 & 230 & 40 & 120 & 38 & 14 & straight & 2.19 & \\
\hline
\end{tabular}

In order to research the effect of different blade stabilizers on cuttings transport efficiency and ROP in vertical wells, field tests were conducted in four mediumdeep vertical wells in a block of Daqing Oil Field in 2010. This block is moderate in difficulty to be drilled, and the common packed hole assembly is used to control deviation, so the primary task in drilling operation is how to improve ROP. The four test wells were carried out in the same layers, which almost have the same depth and lithology. In these tests, the same drilling fluid system and PDC bits were used, and controlling drilling parameters such as hydraulic parameters and bit weight remains the same to a maximum extent. As field tests data is listed in Table 3, the results showed that straight blade stabilizers could achieve higher cutting transport efficiency compared with helical one, bit balling and pipe sticking issues were improved in the drilling operations, ROP was increased more than $15 \%$ in average.

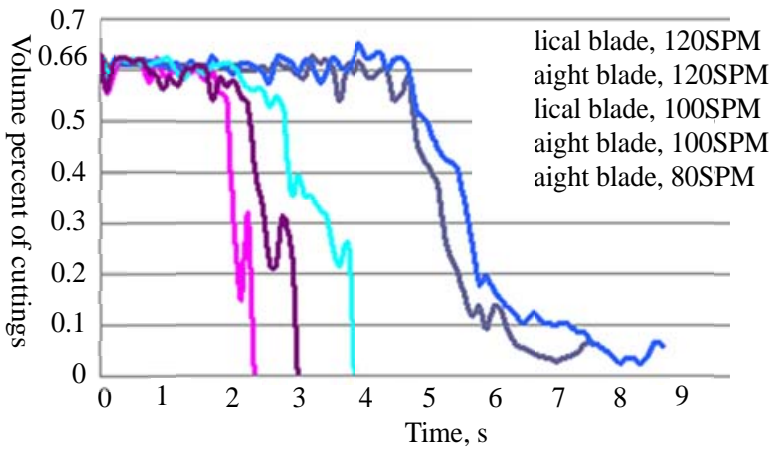

Fig. (6). Time-consuming Curves in diffident pump displacement of two types of stabilizers.

Field tests.

\section{CONCLUSIONS}

(1) Field tests and numerical simulations indicate that under the normal drilling condition straight blade stabilizer is obviously better than helical blade in cuttings transport efficiency in vertical wells.

(2) Under rotatory drilling condition, the blade type of stabilizers significantly affects the flow field distribution and cuttings transport efficiency. When drilling fluid flows through helical blade stabilizers, path lines present large angle deflection, which is not beneficial to enhance cuttings transport efficiency.
(3) The selection of stabilizer's blade shape should consider not only well-wall stability and hole deviation control, but also hole cleaning problems.

(4) The prediction is that there still exist blade shape optimization problems in the drilling process of other type wells, such as complex structure well, extended reach well and so on. Blade shape optimization should be paid more attention, and considered as a potential way to improve hole cleaning problems, decrease repeated fragmentation and enhance ROP.

\section{CONFLICT OF INTEREST}

The authors confirm that this article content has no conflicts of interest.

\section{ACKNOWLEDGEMENTS}

The support of National Science and Technology Major Project of China (No. 2011ZX05009-005) and the National Natural Science Funds of China (No. 51174043) are gratefully acknowledged.

\section{REFERENCES}

[1] H. G. Wang, X. S. Liu, H. Q. Li, and D. Gang, "An experimental study of transport of drilling cutting in a horizontal well", Acta Petrolei Sinica, vol.16, pp. 125-132, 1995.

[2] E. M. Ozbayoglu, A. Saasen, M. sorgun, and K. Svanes, "Estimating Critical Velocity to Prevent Bed Development for Horizontal-Inclined", presented at the 2007 IADC/SPE Middle East Drilling Technology Conference, 2007, pp. 1-6.

[3] M. Q. Duan, S. Miska, M.J. Yu, N. Takach, and R. Ahmed, "Critical conditions for effective sand-sized-solids transport in horizontal and high-angle wells", SPE Drilling \& Completion, vol. 24, pp. 229-238, 2009.

[4] E. M. Ozbayoglu, S. Z. Miska, N. Takachm, and T. Reed, "Sensitivity analysis of major drilling parameters on cuttings transport during drilling highly-inclined wells", Petroleum Science and Technology, vol. 27, pp.122-133, 2009.

[5] T. G. Chen, and Z. C. Guan, Drilling engineering theory and technology. Dongying: University of Petroleum Press, 2000.

[6] Y. N. Su, Anti-deviation and fast drilling for oil and gas vertical well-theroy and practice. Beijing: Petroleum Industry Press, 2003.

[7] Z. M. Chen, "Numerical Calculation for Carrying-cuttings Lifting of Helical Centralizer in Conventional Drilling", Natural Gas Technology, vol. 4, pp. 44-46, 2010.

[8] H. Kinzel, and R.L. Colvard, "Reduce torque, drag and wearmaterial selection for centralizers used in highly inclined and horizontal wells", presented at the 1998 iadc/spe asia pacific drilling conference, 1998, pp. 217-226.

[9] J.G. Boulet, J. A. Shepherd, J. Batham, and L. R. Elliott, "Improved hole cleaning and reduced rotary torque by new external profile on drilling equipment", presented at the 2000 IADC/SPE Drilling Conference, 2000, pp. 1-15. 
[10] R. Ahmed, M. Sagheer, N. Takach, R. Majidi, M. J. Yu, and S. Miska, "Experimental Studies on the Effect of Mechanical Cleaning Devices on Annular Cuttings Concentration and Applications for Optimizing ERD Systems", presented at the SPE Annual Technical Conference and Exhibition, 2010, pp. 1-13.
[11] F. J. Wang, The computational fluid dynamics analysis: (CFD) Software Theory and Applications. Beijing: Tsinghua University Press, 2004.

[12] M. Syamlal and T. J. O'Brien, "Computer simulation of bubbles in a fluidized bed", AIChE Symposium Series, vol. 85, pp. 22-31, 1989.

Received: March 03, 2012

Revised: September 28, 2012

Accepted: October 20, 2012

(C) Xiaofeng et al.; Licensee Bentham Open.

This is an open access article licensed under the terms of the Creative Commons Attribution Non-Commercial License (http://creativecommons.org/licenses/by-nc/3.0/) which permits unrestricted, non-commercial use, distribution and reproduction in any medium, provided the work is properly cited. 